\title{
Inclusions and Exclusions: a Stopes Digital Collection
}

Research for this project was supported through a travel research grant provided by the School of Humanities, Griffith University.

There are no conflicts of interest.

\section{Dr Stephanie Green}

Senior Lecturer

School of Humanities

G.30; 4.24

Southport Campus

Griffith University

Australia

stephanie.green@griffith.edu.au 


\title{
Inclusions and Exclusions: Considerations for a Stopes Digital Collection
}

\begin{abstract}
Investigating a body of archival manuscript research in any field can be a daunting undertaking, particularly when the relevant primary sources are scattered amongst a variety of public and private locations. The creation of a digital collection of privately held manuscripts and minutiae held in private hands offers a boon to researchers who would otherwise be obliged to travel extensively. The digital collection can provide a means of transcending the boundary between private and public access, ensuring that crucial material evidence is available in the public domain. I argue that the interpolation of personal archival materials within the context of the digital public sphere offers a mechanism for investigating sites of knowledge that may otherwise be obscured from history. In the context of women's historical studies, the digital collection offers a means of addressing the Victorian convention of a gendered boundary between private and public spheres. It can achieve this in practical terms, by making previously inaccessible cultural materials available for study or bringing to light work produced by figures who were not already well known. More significantly, it can support further investigation of the complex ways in which women and men were represented as public personae during the late-Victorian and Edwardian periods. This will be discussed with reference to archival material concerning Charlotte Carmichael Stopes and other prominent members of her family, suggesting that the creation of a Stopes Digital Archive exemplifies the value of such mechanisms for further research and scholarly discourse within the context of the digital public sphere.
\end{abstract}

\section{Biographical Note:}

Dr Stephanie Green is Deputy Head of School in the School of Humanities at Griffith University, where she currently teaches writing and literature. She is a widely published, both as a writer and academic. Her major biographical study The Public Lives of Charlotte and Marie Stopes was published in 2013 by Pickering and Chatto (UK). Her scholarly papers have appeared in journals such as Continuum and TEXT. Her recent short fiction and essays have appeared in Griffith Review and Axon.

\section{Keywords:}

Stopes - Archive - Women's History - Private Collection 
Investigating a body of archival manuscript research in any field can be a daunting undertaking, particularly when the relevant primary sources are scattered amongst a variety of public and private locations which present difficulties of access. The creation of a digital collection from unpublished manuscript materials, held in private hands, such as journals, letters, diaries, memoranda and minutiae, may help guarantee their survival, facilitate their availability and offer a boon to international researchers otherwise obliged to travel extensively for their research. In the context of Victorian and Edwardian studies, the digital collection offers a means of addressing conventional assumptions surrounding the gendered boundary between private and public spheres. It can achieve this in practical terms, by making cultural materials available for study that were previously regarded as of minor significance. It can facilitate public engagement in interests and concerns once regarded as private because they were primarily of concern to women. More significantly, it has the potential to support further investigation into the complex ways in which women and men were represented as public personae in this period.

The dispersal and fragmentation of privately owned materials can compound the challenges of producing a coherent archival resource, although no archive can ever be really regarded as complete. Paulus refers to popular and scholarly uses of the term archive as a way of identifying 'an accumulation of physical or digital materials', which can also be an idea a process, or a service. ${ }^{1}$ An archive can be created with a highly specific intentionality or may evolve gradually over time, but will always reflect the dominant ideas of the time and place in which it is created. 'Show me your archive and I'll show you who's is power', Wieringa observes, citing Gloria Wekker, ${ }^{2}$ to make the point that the selectivity of conserved objects and manuscripts reflects the ideologies of the locus and chronology of its creation and the act of interpretation it inevitably generates.

In using the term 'digital collection' my intention is to suggest an assemblage of digital objects which taken together, and possibly linked or related to other digital objects within and beyond the collection, may engender new interrogative frames and platforms for understanding the past. For investigations into women's history, in particular, digitisation may allow cultural materials that have been produced, owned 
and conserved primarily by women to be identified and approached differently, as sources that speak to changing understandings of gender in relation to shifting understandings of private and public identity. In practical terms, the digital collection can thus provide a means of transcending both the geographical and ideological boundaries between private and public discourse, by recording materials not previously prioritised and archived by large institutional repositories. This can allow vital historical and cultural evidence to become available in the public domain, for specialist and non specialist audiences working from different perspectives and widening the scope for scholarly investigations of identity and public influence in the pre-digital era.

Manoff has observed that developing conceptions of the archive in the digital age have altered the ways in which we can think productively about 'cultural memory and historical transmission'. ${ }^{3}$ The interpolation of personal archival materials within the context of the digital public sphere, drawn from archival sources held in private hands, ${ }^{4}$ offers a mechanism for both revealing and interrogating aspects of the cultural value of figures and sites of knowledge otherwise obscured by social and political imperatives. In the context of women's historical studies, the digital collection offers a means of investigating the gendered boundary between private and public spheres, examining the assumptions upon which collection practices were once based and foregrounding previously unremarked evidence of the contributions that women have made to public discourse. The digital collection can open the field and its objects of inquiry to the possibilities for counter-discourses of investigation to emerge. As Chaudhuri, Katz and Perry remark, any archive can be regarded as a methodology for the production of knowledge 'weaving layers of information' together but often to the 'exclusion of documents pertaining to women' ${ }^{5}$ Further, 'even when women are not missing from the archives, reconstructing their lives and voices presents many methodological challenges' due to the fragmentary nature of surviving materials. ${ }^{6}$ The emergence of digital humanities as a frame of inquiry has thus given much greater scope to the potential for comparative evidentiary studies, from which new cultural recognitions may form.

Of course, there may be dangers with an approach where the appropriation and reinscription of private objects and texts is reinscribed and reframed by new 
narratives of the past. Whether these materials are presented physically, for example in a museum or gallery exhibition, or on line, the placement, proximity, naming conventions, and the relational interactions introduced by technology, framing cannot be avoided. As Groys observes, the very act of making public that which was once held privately, is in itself an act of evaluative meaning construction. ${ }^{7}$

This discussion offers a case-based consideration of the benefits and challenges of creating a specialised digital collection of evidence compiled from personal or family archives which reflect the obscured public achievements of nineteenth and early twentieth century women. Such personal or family archives have the potential to alter the sometimes biased, restricted or covert ideological terms within which historical research is undertaken, whether the value framework or disposition of the research is acknowledged or unacknowledged. The digital archive also provides an interrogative mechanism through which contemporary sources used to prove and disprove theories about the past can be investigated and verified. This potential is particularly relevant with reference to accounts of nineteenth and early twentieth-century British women's history; a time when, although women were actively involved in society in potent ways, they possessed relatively limited or tangential access to the discourse of public authority. While women participated in professional activities, from writing and scholarship to medicine, ${ }^{8}$ prevailing cultural narratives tended to consign their thoughts, knowledge and achievements to the realm of the private and personal as of relatively little significance to larger social and political forces at play. ${ }^{9}$ Engel observes that 'Victorian ideology focused on ... limiting potential threats to masculine dominance: women were assigned the role of 'maintaining social peace through the family' as the upholders of domestic beneficence, in order to contain their threatening potentiality as representational figures of autonomous emotion and desire. ${ }^{10}$

Women during this period contributed to society and to public discourse, most noticeably through writing and publishing, in ways that complicate the now musty historical narrative of women as absent or largely subjugated within the cultures of the past. Purvis makes this point in terms of the interrogation of assumptions about 'the broader silencing and marginalization of women's voices from the patriarchal script of history', ${ }^{11}$ pointing out that historical accounts which 
offer a contextualised study of women's experience have created new perspectives, including the recognition that the gendered convention of female domesticity, 'was an ideal rather than a reality for most families'. ${ }^{12}$ Moreover, the 'separate spheres' account of the domestication of bourgeois women in the nineteenth century has been usefully complicated by studies which have shown the extent to which women were in various ways active members of a diverse society. As Kathryn Gleadle remarks, 'the growth of a feminist sensibility' fostered the confidence with which women actively engaged in public life during the second half of the nineteenth century, drawing 'upon a complex mix of cultural influences'. ${ }^{13}$

The problematic reception of female participation in public life is sharply reflected in William Barry's late-Victorian characterisation of the professional achievements of women as an expression of 'intemperate' femininity. In his 1894 essay for the Quarterly Review Barry notes that,

a change has come over society during the last fifteen or twenty years which the author of 'Valentine' could scarcely have foreboded. Women are now graduates in half a dozen professions, and disciples in all. They practise medicine as well as novel-writing; the forceps is familiar to them no less than the bicycle; even dress cutting advertises itself as 'scientific' at six guineas the course. $^{14}$

Following this apparent acknowledgement, Barry goes on to construct the figure of the New Woman, however, as an inauthentic abstraction, exemplifying female emotionalism and inconstancy, her 'dilettantism of impulse' reflecting a dangerously gendered anarchism. ${ }^{15}$ Deriding her 'ridiculous' attempts to 'ape' masculinity, ${ }^{16}$ he concludes that 'the New Woman will not continue long in this land' ${ }^{17}$ Reflective of the rhetorical intensity with which the formative effect of women's active involvement in education, politics and the professions was contested, the passage nevertheless demonstrates that women were indeed, as Walkowizt puts it, making a 'forceful entry into the world of publicity and politics'. ${ }^{18}$

The emergence of middle class women within fields such as education, medicine, business, and writing and publishing, suggests that a clear trajectory existed between the personal lives and public identities of women in the nineteenth 
century and their broader experiences and achievements. The doctrine of gendered domesticity was arguably, then, a partial and unevenly enforced ideological view, which did not wholly reflect the complexity of social and cultural practice, nor indeed the politics of rights discourse in Victorian Britain, as Griffin argues. ${ }^{19}$ Although the two spheres ideology did not take full account of the realities of lived female experience, Barry's essay demonstrates that the notion of the gendered domain retained considerable rhetorical power. Material and legal conditions meant that those who supported equal opportunities for women and men needed to work actively to reframe public recognition of women's position.

Evidence of the extent to which women were engaged in nineteenth century public culture has been made more widely retrievable by the advent of the scholarly digital archive. This is well demonstrated by relevant examples: such as The Orlando Project, ${ }^{20}$ and by Collective Biographies of Women, Booth's work on female prosopography, which is available online as.$^{21}$ Brown, Clements and Grundy argue out that:

Contemporary knowledge about the history of women's writing is a consequence of the extraordinary development, in the last decades of the twentieth century, of academic interest in the recovery of writers who were lost, or forgotten, or suppressed, or ignored. It is also a consequence of the thorough-going critique of a traditional literary history which could not make room for evidence that did not support the grand or canonical narrative. This phenomenally vigorous scholarly work of inclusion — of writers omitted from traditional historical accounts, at least partly by reason of gender or race or class - is arguably the major feature of recent literary historical scholarship. ${ }^{22}$

Just as significantly, the work of women writers is now understood from and within a variety of perspectives, in terms of cultural ideologies, geographical positioning, personal and social conditions. The very category of the personal—with its easily dismissed traces of domestic subjectivity — has become a site of investigation for how interior experiences and quotidian practices can speak to understandings of the past. Burton points out, for example, that given: 
the role of the traditional archive in excluding and distorting women's subjectivity — and of course, all historical subjectivities - making memory history is, arguably one of the grounds from which discussion of women's agency in history must proceed. ${ }^{23}$

It is here, at this intersection within the field of cultural history, between the discursive and the personal, that the digitisation of the private archive can offer crucial opportunities. This is demonstrably so with respect to the digitisation of obscure or hidden material evidence, such as letters, journals, manuscripts, domestic and personal objects, which may facilitate the interrogation and corroboration of established interpretative stances and paradigms by enabling comparative investigation of various archival sources. Further, as suggested at the outset of this discussion, recognition of the digital turn within the humanities offers scope for new modes and counter-discourses of investigation to emerge, new pathways of meaning making and mechanisms for information recovery. These developments are significantly changing how we approach documentary research, enabling multilayered and multi-directional encounters, and recruiting experiential and biographical accounts to inform research. Jones observes that;

the new digital humanities starts from the assumption of a new, mixed-reality humanities, complicated and worldly, mediating between the physical artefacts and archives on which humanities discourse has historically been built, and the mobile and pervasive digital networks that increasingly overlay and make those artefacts into data-rich, tagged and encoded, sensor-enhanced things. ${ }^{24}$

From this perspective, the materiality of the traditional archive can hardly said to be lost, even through its transformation and re-manifestation as digital culture: a context in which the pursuit, interpretation and communication of evidence, as the basis for understanding cultural heritage and its contemporary impact, remain primary goals. Yet while a trail of material artefacts may provide the originary sources or evidentiary points of reference upon which historical archives are built, within the digital cultural sphere these may also have a life beyond the boundaries of the archival space, allowing new connections and comparisons to be made, new dialogues to be generated, and new understandings to be realised and shared. The digitisation of archival materials relating to women and others in history and the 
interpretative culture surrounding them has been, and will continue to be, of vital importance in achieving a rich, nuanced, multi-disciplinary and culturally inclusive approach to understanding the past and its lasting influence.

The historicist narrative of the unrecognised but determined emergence of women as contributors to the public agenda is reflected in the case of the latenineteenth century cultural historian Charlotte Carmichael Stopes (1840-1929). Her inter-generational influence was marginally acknowledged for much of the twentieth century but has emerged as a topic of interest for feminist scholars over the past two decades. ${ }^{25}$ Now recognised as an important pioneer figure in accounts of the women's movement in Britain, ${ }^{26}$ she had been regarded as an obscure and tangential fuddy-duddy eccentric, portrayed predominantly as the problematic mother in biographies of her prominent and controversial early daughter, Marie Stopes. ${ }^{27}$ As a result, only a limited selection of Charlotte Stopes's manuscript materials and personal papers was preserved by public collection agencies, whose main focus was concerned with the work and life of her daughter, and by family members. At the time of Marie Stopes's death, a large quantity of documents was destroyed, including items that related to her parents. ${ }^{28}$ The loss of this material is regrettable but as in so many such cases, perhaps inevitable.

Charlotte Stopes played a key role in the mid-late nineteenth century women's movement as a pioneering member of the earliest women's higher educational associations in Scotland, during the $1870 \mathrm{~s},{ }^{29}$ and was the first woman in Scotland to take a university qualification. ${ }^{30} \mathrm{~A}$ successfully published independent writer and scholar, she showed the importance of women's history as a means of contesting contemporary prejudices against women and was one of a 'new generation of university educated women who combined her interest in feminist activities with a keen interest in women's history'. ${ }^{31}$ Her study of women and public leadership in British history, British Freewomen, was a cornerstone for two generations of suffrage activists. Alongside her work for social change, she was also a scholar of the English literary Renaissance, producing numerous books and papers in the field. ${ }^{32}$ She received an award from the British Academy in 1916 for her Shakespearean research, but her study of British women's history, British 
Freewomen (1894) was arguably the most broadly influential of her many publications.

Charlotte Stopes's literary scholarship has been dismissed in some quarters, ${ }^{33}$ and lauded in others. ${ }^{34}$ As a researcher, however, she was important in terms of helping to build a foundation for twentieth century scholarly practice, and shaping bourgeois public appreciation of Shakespeare's plays as the Shakespeare expert for The Athenaeum. ${ }^{35}$ She is interesting, moreover, as a figure that both embodied and yet resisted some of the dominant cultural tropes of her time, seeking to be a wife and mother in her late thirties, at a time when women of her age might have seemed unmarriageable, while also pursuing her own work as a writer and scholar. In her private life, as in her public achievements, she wrestled with the personal and social expectations of her gender, including domesticity and sexuality. Consigned to the margins of the British academy, Charlotte Stopes's legacy was overtaken by twentieth century transformations and revaluations in the fields of both Shakespearean scholarship and feminism. Surviving manuscript materials within the Stopes-Roe family archive include autobiographical notes and letters from longstanding colleagues reflect her feelings about the constraints of her gender, ${ }^{36}$ and her recognition that her moments of public prominence arose as much from her work for the women's movement than from her scholarly endeavours. ${ }^{37}$

A sense of purpose in public work was, of course, shared by other members of the Stopes family. During her late thirties Charlotte married brewery architect, engineer and geology enthusiast, Henry Stopes (1852 - 1902), a noted figure amongst the scientific intelligentsia of his day who made some significant palaeolithic finds. ${ }^{38}$ Henry was a prominent spokesman for the pure beer movement, ${ }^{39}$ stood for parliament unsuccessfully, was bankrupted and spent his declining years occupied as an amateur field geologist, sifting stones in the Thames estuary. The couple produced two daughters, the eldest of whom was the paleobotanist and highly publicised sex educationalist and birth control advocate Marie Stopes (1880-1958).

Charlotte and Henry Stopes were, in the broadest sense, exemplary middle class Victorians. They worked hard, upheld religious values, read widely, attended cultural assemblies, public lectures and meetings of the British Association for the 
Advancement of Science and regarded themselves as informed, progressive and questioning members of the London intelligentsia. ${ }^{40}$ They joined political campaigns and lobby groups, became thorough researchers who published their evidence and ideas, and considered it an essential part of their work to become persuasive public speakers. ${ }^{41}$ And they inculcated similar values in their eldest daughter. In different ways, although little remembered, Charlotte and Henry thus both sought to contribute to social change. Together, they taught their daughters to live as they had done, through achievements in writing, scientific discovery, cultural appreciation and social progressivism. Through Marie, even more powerfully than through their own efforts, their private lives became enmeshed with public history. Their early correspondence has been read as significant for revealing sexual fissures in their relationship, which Hall argues contributed to Marie's interest in the importance of sexual intimacy in marriage, but their relationship was also clearly affected by a variety of external factors. Over the two decades of their marriage, they formed a mutually supportive, unusually equal and autonomous partnership which enabled each to pursue their interests while they brought up their two daughters in the London suburb of Hampstead. ${ }^{42}$

One of the most provocative and influential women of her day, now best known as a contraception advocate and sex-educator, Marie Stopes began her academic career as a brilliant young palaeontologist, gaining doctorates from the Universities of Munich and London. Although she initially resisted identification with the feminist movement, which she associated with the dusty earnestness of her mother's generation, she exemplified the new and radical possibilities for women. She wrote several polemical books and plays, including her sexual conduct guide Married Love (1918) and the censored play Vectia (1927) which dealt with the then scandalous topic of women's sexual ignorance. ${ }^{43}$ Marie's views may be regarded as particular to their historical and cultural moment, but her work as a writer and educator contributed significantly to lasting changes in the history of sexuality in western culture, leading to profound changes for middle class families and for women in working life. Her change of career direction has been associated with the demise of her first marriage, to Canadian scientist Reginald Ruggles Gates. ${ }^{44} \mathrm{Her}$ successful petition for annulment of the marriage was publicly played out in the courts and the press. Indeed the story of Marie Stopes, as related by biographers, 
historians and cultural analysts, is well established in the annals of human sexuality studies. ${ }^{45}$ As Ross McKibbon points out, the allegation of sexual dysfunction 'was the only way Stopes could get out of a failed and unhappy marriage' because the law would not allow her to divorce at that time, in either Canada or England. ${ }^{46}$

In related ways, the public careers of these three prominent members of the Stopes family were shaped by prevailing cultural narratives, including the emergence of Darwinian theories of evolution and natural selection, changing attitudes towards female sexuality and intellectual capacity, including debates about 'the woman question'. Their letters show that they supported each other's research and public campaign efforts on a variety of fronts, but their sympathy for each other's work was also coloured by individual issues and concerns. Ruth Hall and others have argued that Charlotte and Henry's marriage was damaged by sexual incompatibility and that this was one of the factors that mobilised Marie to confront the debacle of her unhappy first marriage; seeking a legal annulment and writing the internationally controversial Married Love. ${ }^{47}$ Elsewhere I suggest that sexual repression may not have been the only, or even the overriding point of conflict between Henry and Charlotte Stopes. ${ }^{48}$ Charlotte was clearly anxious about the security of her personal and financial situation from very early in their marriage, when Henry broke away from the family brewery business in Colchester to set up on his own. ${ }^{49}$ Even during their honeymoon trip to Egypt and Europe, she felt intermittently abandoned by her husband's absorption in business dealings and scientific interests, often away from her for long periods. ${ }^{50}$ At the same time, she was an intellectually ambitious woman who took opportunities to forge an independent identity as a scholar and activist.

The point that the alleged boundary between women's domestic and public lives in this period was highly complex and permeable is well demonstrated by Charlotte's experiences and achievements. After giving birth to two daughters in her early forties, she dealt with Henry's mercurial absences by immersing herself in writing and political causes. The rift that emerged in their relationship at the end of the 1880s was partly provoked by Henry's bankruptcy and the forced sale of their London home in 1892. According to Colchester newspaper the Essex Standard, he was arrested and briefly incarcerated at Holloway gaol for non-payment of debts at the end of January $1892 .{ }^{51}$ Charlotte enrolled her daughters at St George's School of 
Girls in Edinburgh and returned to Henry. After a difficult period together in Swanscombe, she rented quarters in Torrington Square, Bloomsbury. ${ }^{52}$ This enabled her to pursue her work at the British Museum Library and her political involvement in the women's movement, which included membership of the Women's Emancipation Union and the Women's Progressive Society. ${ }^{53}$

Henry and Charlotte lived apart for much of the last decade of their marriage, but spent time together and remained on cordial terms. When Charlotte wanted her daughters to go to Mary Buss's North London Collegiate School for Girls, Henry took a house in Hampstead for the family but retained Mansion House in Swanscombe for himself. ${ }^{54}$ Their second daughter, Winifred Stopes, suffered from ill health throughout her life and was overshadowed by the other high achieving family members. Winnie nevertheless offers an interesting example of the ways in which privately recorded traces carry the texture of social, cultural and spiritual practices through the ephemera that survived her: from spiritualist tracts and herbalist pamphlets to the few remaining volumes she bound by hand in brown leather.

The Stopes family, with its plethora of fortunes and failures, offers a rich encapsulation of themes, issues and ideas relevant for historians and biographers interested in the study of Victorian middle class culture in the last decades of the nineteenth century. Yet, their legacy is only partially known and has been, at times, subjected to distortion. Charlotte's later-life identity as a crusty and obscure eccentric, following Henry's death in 1902, was shaped both by her feminism, her dedication to research and by financial worries, but this reputation did not reflect her earlier contributions to history, literature and society. Her achievements were inevitably overshadowed by those of her famous daughter, Marie Stopes, while her husband's efforts to make a mark in the world were even less known. Moreover, while Marie became a highly recognised figure, as an advocate for women's sexual health issues, she has also been the subject of considerable misrepresentation in the press.

The publicly available material evidence for accounts of these three figures, their context and influence, is spread throughout a variety of resources in Britain. A substantial archive of Stopes manuscripts is available to researchers at the British 
Library in London which includes several volumes of correspondence and other personal papers. This is complemented by sources available at the Wellcome Institute Library and the Women's Library at the London School of Economics. Additional documentary sources are also available at the Rylands Library, Manchester, University College London Special Collections and the British National Archives, while the Henry Stopes geological collection is held at the National Museum of Wales. The construction of a comprehensive Stopes digital archive, drawing on contributions from the major as well as the minor collecting agencies, would be a massive logistical effort, encompassing the resources of many people and institutions and requiring a complex process of image production, permissions and digital information management. Moreover, these materials are publicly available for scholarly inquiry. It is, rather, the smaller collections of nevertheless vital materials, which make up the current private archives whose fate is somewhat uncertain, and which are not easily accessed by international scholars, that would provide the most valuable and manageable core content for a Stopes Digital Collection.

Key documentary evidence is held, however, with the Stopes-Roe family archive in Birmingham. ${ }^{55}$ These papers which have been privately preserved are among the most important evidence of the factors which affected Stopes family relationships, including those which may have influenced Marie Stopes towards pursuing a public, rather than an academic, career. The documents intimately reflect the values and priorities of the time, and may enable a revaluation of assumptions and interpretative stances previously advanced by biographers and cultural historians. In addition to the Stopes-Roe family archive in Birmingham, crucial items relating specifically to the work of Henry Stopes are currently held under the custodianship of Dr Francis Wenban-Smith. ${ }^{56}$

While other items of historical importance are held in repositories which have faced changing and sometimes uncertain circumstances, such as the Women's Library, now based at the LSE, and the Special Collections archive at University College, London. These private archival collections include early letters between Charlotte and Henry, journal publications, manuscripts, letters, drawings, books, photographs and correspondence with leaders in the fields of science and literature. Noteworthy items amongst the collections are correspondence between Henry and 
Charlotte from the period leading up to and shortly after their marriage, Henry's research notes, correspondence and architectural drawings, Charlotte's honeymoon tour diary, Charlotte's draft autobiography and various later correspondence from a later period in Charlotte's life with friends and members of the various associations of which she was a member. These materials are fragile, many are written by hand, finely-inscribed, occasionally in crossed lines, demanding careful and repeated reading.

These facts all demonstrate the value of strategic accessibility that a Stopes digital archive would offer to researchers. Such a resource would be an important strategy in preserving documentary evidence for future researchers. Of course an online digital archive need not only be a practical resource. It could also offer a platform for scholarly dialogue and debate about contexts, references to contemporary issues and personae, theories and interpretative approaches to documentary materials. The practical advantages of incorporating these materials into an online digital archive would, nevertheless, be worthwhile. At the time of Marie's death in the nineteen fifties, the quantity of her personal and professional records was so great that a considerable proportion had to be destroyed, including some papers of Charlotte and Henry Stopes. While the relevant public cultural institutions demonstrably saw a clear value in terms of the national significance of acquiring selected papers left by Marie Stopes, her parents were at that time regarded as minor historical figures whose claims to posterity were thought to be of modest value. The Stopes-Roe family, who now bore responsibility for the Stopes family archival legacy, confronted with 'three lorry loads' of personal papers rejected by the British Library as of insufficient significance, could afford to retain only what were deemed by the family to be the most crucial items of family interest, and burned the remainder in their suburban back yard. ${ }^{57}$ Although a selection of items that have been of key interest to scholars were preserved, it is impossible to assess the long term significance of what may have been lost.

Of course no repository, whether public or private can keep 'everything'. Public collections must make choices about what they collect in terms of perceived national interest and long term value or national significance. The British Library's collection development policy states that while "no library can aspire to being 
comprehensive in its coverage of the world, the British Library collects widely and in depth in its areas of traditional strength' and identifies its purpose as representing 'the collective memory' of the British nation. ${ }^{58}$ The necessity for selectiveness and the decisions which govern the inclusion of manuscript materials within any public collection must be, necessarily, informed by the values and priorities of the collecting agency. Library and archival collections are not only selective in what they collect, but have a formative role in shaping the way that users can learn about and use information. Systems for selecting, storing, catalogue ordering, displaying and interpreting material evidence will reflect the 'attending power structures and the cognitive projects of the archivist', ${ }^{59}$ which reflect the values and ideas which have dominance and currency within the society. What is regarded as of public and historical value will therefore be determined by the prevailing values of the cultural institution at the time of acquisition.

The methodology of the archive thus has a discursive function, as with all methods of meaning making, the collecting and arranging of information inherently shapes the use of that information and our understandings and beliefs about the past. As Foucault argued, an archive may encompass many possibilities for expressing knowledge, but cannot be in itself ever entirely complete. This is not because not archive can keep 'everything', but because as a discursive system the archive facilitates, but also limits particular kinds of participation and engagement. ${ }^{60}$ In the sense, then, that public libraries, collections and archives reflect the discursive priorities, publications, documents, policies, people and events of the past, these resources must necessarily reflect their bias. Consequently, institutionalised collection policies and practices have a direct bearing on the development of historical accounts, which so often rely on the material evidence these institutions hold.

The challenge of gathering and maintaining those elements of western cultural history that have been traditionally subjected to ideological discrimination is arguably demonstrated by the experience of the Women's Library, London. First constituted from the collected papers of suffrage activist Millicent Garrett Fawcett, the collection has occupied a variety of venues over the past century. Its purpose is to 'documents all aspects of women's lives, with a particular emphasis on the lives 
of women in the UK and the great political, economic and social changes of the past 150 years' ${ }^{61}$ The national, and indeed international, significance of the Women's Library was recognised in 2007 when the National Museums, Libraries and Archives Council granted its collections Designated Status to the collections. ${ }^{62}$ The agency has had significant difficulties finding an established home for its collection, being ejected from its purpose-built accommodation in $2013 .{ }^{63}$ The example of the Women's Library offers a pungent example of the lasting challenges of maintaining and communicating women's history and provides further evidence that the digitisation of archival materials held in private hands is vital for the survival and reevalution of collective memory. Yet even a digital collection requires a host some form of personal, institutional or publication framework - if it is to survive, especially in an internationally accessible form.

The Stopes-Roe family archive has been a valuable resource for generations of researchers in search of evidence related to the life of Marie Stopes and, to a lesser extent, her ambitious parents. Items held with the Stopes-Roe archive, such as press cuttings, photographs, unpublished manuscripts and correspondence have been important for the many biographical accounts of Marie Stopes. They have been equally important for the revaluation of Charlotte Stopes as a notable late nineteenth and early twentieth century literary scholar, and for investigating and contextualising Henry Stopes's scientific endeavours. ${ }^{64}$ Accessed by way of a steep ladder stair at the top of the house, this archive has been kept under the sloped ceiling of an attic whose centrepiece is a dusty tennis table, surrounded by stacks of boxes, files, cabinets, and a bank of library shelving, with a small window overlooking the yard.

Much of this material has and continues to be necessary in providing evidence for continued investigations and understandings of the life and work of Marie, Henry and Charlotte, as well as the intellectual context they inhabited. Indeed some of this material has only recently come to light, having been hidden away in a deep recess of the Stopes-Roe family attic. At the end of 2012, as I was in the final stages of writing a monograph about Charlotte and Marie Stopes, Harry and Mary Stopes-Roe wrote to tell me that a box had just been found, containing correspondence between Charlotte and a number of prominent figures with whom she was associated during her later years. ${ }^{65}$ As I could not travel to the UK at short 
notice and my manuscript deadline was imminent, I employed a research assistant to photograph the items and send the images to me. ${ }^{66}$ Several of these items enabled me to confirm suppositions and find support for key points, demonstrating the value of the archive but also serving as a reminder of the limits of material inaccessibility. The anecdote illustrates the sometimes ad hoc nature of dealing with a private archive, without formal filing and storage systems for archive management. As with any collection in private hands, the survival of these private archival collections is reliant, along with their accessibility, on the changing circumstances, resources and interests of individuals. Although a sterling effort has been made to organise the family collection, in particular by Mary Stopes-Roe, its storage and management has not been a simple matter for the family to arrange. Some items have had to be gradually sold, loaned or donated to collecting agencies. With the recent death of Marie's son, Harry Stopes-Roe,${ }^{67}$ the collection now rests in the hands of the remaining family members and the future and integrity of the collection is yet to be determined.

In the aftermath of producing a contextual study of the lives and work of Charlotte and Marie Stopes ${ }^{68}$ the value of a creating a consolidated and digitised Stopes archive of privately collected materials has become evident. Such an archive would contain key documents of relevance to British public history of the late nineteenth and early twentieth centuries. Equally, it would contain documents of personal relevance to the lives of Stopes family members, which also shed light on the continuities and discontinuities between their professional and private concerns. A Stopes digital archive would, in addition, be of practical use to scholars, due to the geographical distance of archival collections currently held in private hands; in Birmingham and Southampton. While important manuscript materials relating to the Stopes family are now available in material form to researchers by way of public repositories, key items of considerable significance can only be accessed by personal request and at the convenience and generosity of the present archive guardians.

Furthermore, a Stopes digital collection would allow scholars to address the gaps and limitations that may exist within the body of research that has been able to be undertaken, to date. Of course, a digital archive is no simple matter to create, nor is it without some of the attendant complexities and challenges that a paper archive 
presents. Practical considerations such as the availability and suitability of certain objects and items for digitization, decisions about categorisation, the order or hierarchy of document retrieval and the lateral links between items records, are significant challenges in the construction of a data repository of this kind. Even more importantly, matters such as the central organising principles, conceptual framework, and audience identification must be clearly established at the outset. In the case of Stopes digital archive, where long term value is one of the criteria of importance; risks to the archive include web-based challenges such as host provision and software redundancy. ${ }^{69}$ This is less of a problem perhaps that it was at the outset of the digital archive transition, at a time when it was considered that; 'Humanists pose a special problem for preservationists because they are adopting digital technologies to create highly complex, often idiosyncratic digital objects'.$^{70}$ Indeed, arguably, the need for digital 'objects' which challenged technological and generic parameters have helped to create a digital cultural sphere which enables scholars in the Humanities to produce new kinds of research, including rich resources and interpretative frameworks for their colleagues. As the creators of the Orlando database remark:

Orlando's differences as literary history arise largely from its integration of readable text and electronic structure. That is why we call it a textbase rather than a database: it returns results in prose rather than in tabular form. Its content and means of delivery are inseparable and essential elements of one project. They were built together, making Orlando highly responsive to questions its readers ask. ${ }^{71}$

As digital technology rapidly becomes more adaptable, more easily and widely shared, and tailored for online communication, including social media, digital object preservation has already become less cumbersome. The expansion of the digital cultural sphere has given rise to the emergence of new sites of public exchange and new modes of engagement. This undoubtedly means that how archival information is used is less able to be contained within institutional bounds. This brings risks as well as opportunities, but points to a recognition that the digital cultural sphere is now the primary medium through which information is viewed, retrieved, used, exchanged and, moreover, discussed and debated. The digitisation of 
women's material history can thus give greater flexibility and accessibility to the way key resources are shared and recruited, both for academic and non-academic researchers, with fluency and immediacy.

These remarks are not intended to discount the problems posed by maintaining a digital archive. The access and retrievability of materials in database formats may rely on the good will and resources of a host organisation such as a university, research library or publicly funded repository. Some such organisations may restrict membership, although the advent of open source publishing has improved accessibility. Considerable flexibility and economy is now available through non-institutional web-based platforms, however these do not necessarily possess the research credibility that more formal institutional frameworks provide. While non-institutional platforms may well have appeal for those working on the ante-narratives of society, culture and identity, sensitive to the history of exclusionary discourse, the demands for academic scholars to produce work within the zones of legitimation may demand continued negotiation to achieve the long term survival of marginal cultural repositories. Digital formats are subjected to continual change, requiring regular updates. Moreover, access to the web itself remains culturally and economically determined. As Lesk argues, however, the challenge of digital preservation is not inherently one of technology: preservation relies on organisation knowledge, cultural values and resourcing. ${ }^{72}$

Of course, no single archival project can completely solve the problem of managing and preserving material objects such as books, manuscripts and photographs. In a culture dominated by digital communication, paper-based archives may become vulnerable to neglect, in terms of both material survival and digital selectivity. Scholars cannot afford to assume that the evidence that makes it into the digital arena necessarily tells the whole story or even the right part of the story. Those archives that record and demonstrate the important and distinctive contribution of women to public culture and social discourse are particularly vulnerable to diminishment. The example of the Women's Library, as discussed, demonstrates the extent to which vital aspects of women's history remain subject to the vagaries of lasting ideological priorities and concomitant changes in institutional policy. Embedded marginalisation remains an undercurrent in the lived experience of 
women. Even so, the benefit of the broader project of digitising the evidence for women in history can to help remind readers, viewers and scholars that women were active, assertive, informed and influential, and, simultaneously, that the conditions in which they operated were challenging to the recognition of their diverse contributions in a number of ways. The way forward for this scholar, therefore, includes the scoping and pursuit of funding for a Stopes Digital Archive. Key documents, including correspondence, visual materials, manuscripts and items such as press clippings which reflect contemporary cultural narratives, will be the centrepiece of the archive. These will be contextualised in a variety of ways, through captions, scholarly research discussion and links to relevant information.

The diversification and development of new research perspectives in the humanities has highlighted the importance of keeping questions of social and cultural inclusiveness in view, and has raised recognition of the potential for cultural shifts that may reveal once seemingly trivial or marginal information as valuable, even central, to contemporary understandings of the past. The point that both Charlotte and Marie Stopes have been represented in ways that reflect cultural prejudices about female identity is relevant here. In particular, the figure of Marie Stopes has been employed with great prominence, in a variety of ways and purposes in relation to human sexuality and identity over the past century. As a public figure she has encapsulated multiple public personae; stellar career scientist, female sexual liberationist and sensible family planning advocate, and eugenicist. ${ }^{73}$ The child of progressive Victorians who encouraged her to believe that women were equal with men, Marie Stopes also held conventional views about sex as an expression of love within the bounds of heterosexual marriage and about the value of human life. References to her name, before and since her death, reflect a continuing process of reinvention and repositioning in terms of her controversial public identity, as exemplified by surprisingly fierce internet debates about her appearance in a series of commemorative postage stamps produced by Britain's Royal Mail. ${ }^{74} \mathrm{Her}$ infamous identity has often been manipulated, for example, through accusations that she promoted abortion, although, in fact, she abjured the practice. ${ }^{75}$ This point in itself suggests the value of digitized resources, for both scholars and social commentators, of access to evidence as a means of interrogating the changing politics of popular rhetoric over time and in different social and geographical 
contexts. Her name remains a touchstone for both positive and negative aspects of social transformation during the inter-war period. As Cohen argues, nevertheless, her advocacy of birth control 'was governed not by her loudly-proclaimed eugenic allegiances, but by her concern for the happiness and health of the individual woman' of all classes. ${ }^{76}$

The creation of a Stopes digital archive would enable the controversial biographical history surrounding Charlotte, Henry, and Marie Stopes and their milieu to be investigated with reference to the evidence, virtually at first hand, by scholars around the world. As I suggest with reference to Marie Stopes in particular, this kind of immediacy of access may enable some of the prejudices, assumptions and discourses that have been invoked in relation to the Stopes narrative to be reevaluated. Without direct access to the past, cultural historians must be aware of what we bring to our interpretations of historical evidence, our assumptions about how people lived and what they believed. ${ }^{77}$ Even with reliable evidence at our disposal, we must acknowledge that the cultural politics of our own assumptions will shape our understandings of the material evidence at our disposal. In recounting the history of women's lives, for instance, we do well to test and interrogate what we assume about the limitations and liabilities of opportunity and discrimination in lateVictorian and Edwardian Britain. The digitisation of personal and public materials held in private archives, offers opportunities to make available otherwise a much wider scope of information to a much more diverse range of interpretative voices. While inclusion and diverse access do not ensure an inclusive or multifaceted approach to research, the digital archive can enable a process of inquiry and ideological contestation to occur in new ways and from new perspectives, over time.

\footnotetext{
1 Paulus Jr, Michael J. (2011) 'Reconceptualizing academic libraries and archives in the digital age', portal: Libraries and the Academy 11.4 939-952, p. 940.

2 Wieringa, Saskia E. (Ed.) (2008) 'The (Sexual) Revolution of the Amsterdam Women's Archive and Library', Traveling Heritages: New Perspectives on Collecting, Preserving, and Sharing Women's History (Amsterdam: Amsterdam University Press), pp. 9-19, p. 11.

3 Manoff, Marlene (2010) ‘Archive and Database as Metaphor', portal: Libraries and the Academy 10.4, p. 385.

4 Stopes-Roe Family Archive, Birmingham: Wenban-Smith Archive, Southampton.
} 
5 Chaudhuri, Nupur, Sherry J. Katz, and Mary Elizabeth Perry (2010) Contesting Archives: Finding Women in the Sources (Chicago: University of Illinois Press), p, xiv,

6 Chaudhuri, Katz and Perry, Contesting Archives, p. xv

7 Groys, Boris (2013) 'Entering the Flow: Museum between Archive and Gesamtkunstwerk', «e-flux Journal 12.2013, p. 50 at: http://www.e-flux.com/journal/entering-the-flow-museum-between-archive-and-gesamtkunstwerk/ [accessed May 12, 2015)

8 Palmer, B. (2011) Women's Authorship and Editorship in Victorian Culture: Sensational Strategies (Oxford and New York: Oxford University Press), pp. 4-8: Carpenter, M. W. (2010) Health Medicine and Society in Victorian England (Santa Barbara: Greenwood), pp. 174-176.

9 Harrison, B. (1978/2013) Separate Spheres: the Opposition to Women's Suffrage in Britain (Abingdon, Oxon: Routledge), p. 40.

10 Engel, S. M. (2001) The Unfinished Revolution: Social Movement Theory and the Gay and Lesbian Movement (Cambridge; Cambridge University Press), pp. 150-151.

11 Davies, H. (2012) Gender and Ventriloquism (London and New York: Palgrave, Macmillan), p. 69.

12 Purvis, J. (1997) Women's History: 1850-1945: An Introduction (London and New York: Routledge), p. 40.

13 Gleadle, Kathryn (2001) British Women in the Nineteenth Century (London \& New York: Palgrave/Macmillan), p. 154.

14 William Barry (1894) 'Intemperate Cleverness. The Strike of a Sex', Quarterly Review Vol. 179, pp. 289-318, in Ann

Heilmann (Ed.) The Late-Victorian Marriage Question: A Collection of Key New Women Texts, Vol 5 (London \& New York: Routledge), p. 294.

15 Barry, Intemperate Cleverness, p. 293.

16 Barry, Intemperate Cleverness, p. 314

17 Barry, Intemperate Cleverness, p. 317.

18 Walkowitz, J. (1992) City of Dreadful Night: Narratives of Sexual Danger (Chicago: Chicago University Press), p. 7.

19 Griffin, B. (2012) The Politics of Gender in Victorian Britain (Cambridge: Cambridge University Press), pp.3-21.

20 Brown, S., Clements. P., Grundy, I. (2006) Orlando Project at: http://orlando.cambridge.org/ [accessed July 12, 2015)

21 Booth, A. (2004) Collective Biographies of Women at: http://womensbios.lib.virginia.edu/ [accessed June 20, 2015).

22 Brown, Clements, Grundy, Orlando Project at: http://orlando.cambridge.org/

23 Burton, A. (2003) Dwelling in the Archive (Oxford: Oxford University Press), p. 28.

24 Jones, S. (2013) The Emergence of the Digital Humanities (London and New York: Routledge), p.32.

25 Demoor, M. (2009) Dictionary of Nineteenth Century Journalism in Great Britain and Ireland (Gent: Academia Press), p.

987: Prince, K. (2008) Shakespeare in the Victorian Periodical, (New York: Routledge), pp. 45-47: Delap, L. (2006) Feminism and the Periodical Press 1900-1918 (Abingdon, Oxon: Taylor \& Francis): Blain, V., Clements, P., Grundy, I. (1990) The Feminist Companion to Literature in English (London: Batsford), p. 1034.

26 Mayhall, L. E. N. (2000) ‘Defining Militancy: Radical Protest, the Constitutional Idiom, and Women's Suffrage in Britain, 1908-1909', Journal of British Studies 39.3, p. 350.

27 Garrett, W. (2007) Marie Stopes: Feminist, Eroticist, Eugenicist (San Francisco: Kenon Books), p. iv: Rose, June (1993) Marie Stopes and the Sexual Revolution (London: Faber and Faber), pp. 19-21: Hall, Ruth (1977) Passionate Crusader: The Life of Marie Stopes (London: Harcourt, Brace, Jovanovich), pp. 23.

28 Harry Stopes-Roe, personal comment, June 25, 2012.

29 Sarah Mair to Marie Stopes, Stopes Correspondence, Stopes-Roe Family Archive, March 30, 1929: Holton, S.S. (2000) 'The Making of Suffrage History' in J. Purvis and S. Holton (Eds) Votes for Women (London: Routledge), pp. 14-16

30 Blain et. al., Feminist Companion, p. 1034.

31 Purvis, Women's History, p. 3.

32 McLuskie, K. (2013) 'Remembering Charlotte Stopes' in G. McMullan, L.Cowan Orline and V. Mason (Eds) Women Making Shakespeare: Text, Reception and Performance (London and New York: Bloomsbury Arden Shakespeare), pp. 195-206.

33 Schoenbaum, S. (1991) Shakespeare's Lives (Oxford: Oxford University Press), p. 460.

34 William Poel to Marie C. Stopes, Stopes Correspondence, Stopes-Roe Family Archive, October 101928.

35 Prince, Shakespeare in the Victorian Periodical, pp. 45-47: Demoor, M. (1995) 'An Honourable Gentleman Revisited: Emilia Strong Pattison's noted entry into the world of Sir Charles Wentworth Dilke and the Athenaeum', Women's Writing 2.3, pp. 201219. 
36 William Poel to Marie Stopes, 8 February 1929, Stopes-Roe Family Archive.

37 Stopes, C. C. (c.1920-1922) ‘Autobiographical Notes’ IV, Stopes-Roe Family Archive.

38 Wenban-Smith, F. (2010) 'Henry Stopes (1852-1902): Engineer, Brewer and Anthropologist', in R. Hosfield, F. WenbanSmith \& M. Pope (Eds) Great Prehistorians: 150 Years of Palaeolithic Research, 1859-2009 in Lithics sv30, pp. 65-84.

39 Clark, Christine (1998) The British Malting Industry Since 1830 (London \& Rio Grande, Ohio: Hambledon), p. 68.

40 Hall, Passionate Crusader, pp. 18-28.

41 Henry Stopes to Charlotte Carmichael, Stopes Papers, Wenban-Smith Archive, Aug-Sept 1880.

42 Hall, Passionate Crusade, p. 19-21: Green, S. (2013) The Public Lives of Charlotte and Marie Stopes (London: Pickering \& Chatto), pp. 50-52.

43 Sullivan, E. B. (2005) 'Vectia, Man-made Censorship and the Drama of Marie Stopes', Theatre Survey 46.1, pp. 79-102. 44 Rose, Marie Stopes and the Sexual Revolution, p. 72-73.

45 Hall, Lesley. A. (1993) 'Uniting Science and Sensibility: Marie Stopes and the Narratives of Marriage in the 1920s', in A. C. Ingram and D. Patia (Eds), Rediscovering Forgotten Radicals: British Women Writers, 1889-1939 (Chapel Hill \& London: University of North Carolina Press), pp. 118-127.

46 McKibbon, R. (2004) Introduction, Married Love, (Oxford: Oxford University Press), pp. vii-xIi.

47 Rose, Marie Stopes and the Sexual Revolution, pp. 19-21.

48 Green, Public Lives, pp. 47-51.

49 Stopes, C. C. (c.1920-1922) 'Autobiographical Notes’ I, pp. 8-9.

50 Briant, Keith (1962) Passionate Paradox: The Life of Marie Stopes (London: Norton), p. 20.

51 'Bankruptcy of Mr Henry Stopes', Essex Standard May 21 1892, p. 2.

52 Charlotte C. Stopes to Marie C. Stopes, British Library Manuscripts Collection, Add. 58449, f. 85, 28 March 1894.

53 Green, Public Lives, pp. 97-98.

54 Henry Stopes Papers 1892-1900, Wenban-Smith Archive.

55 At the time of writing.

56 Dr Wenban-Smith is an archaeologist with the University of Southampton whose research interests include the Henry Stopes flint collection: http://www.southampton.ac.uk/archaeology/about/staff/ffws.page\#background/ [accessed 2 July 2015].

57 Harry Stopes-Roe, personal comment, June 25, 2012.

58 Collection Development Policy, British Library at: www.bl.uk/aboutus/stratpolprog/coldevpol/ [accessed July 2, 2015].

59 Codebò, M. (2010) Narrating from the Archive (Madison, N.J.: Fairleigh Dickinson University Press), p. 59.

60 Foucault, M. (2004) Archaeology of Knowledge (London: Routledge), p. 54.

61 Women's Library, London School of Economics at:

http://www.lse.ac.uk/library/collections/featuredCollections/womensLibraryLSE.aspx/ [accessed July 25, 2015].

62 'The Women's Library Suffrage Collection', VADS: Online Resource for Visual Arts: London Metropolitan University at: http://www.vads.ac.uk/collections/WLS.htm/ [accessed July 25, 2014].

63 Kennedy, M., Guardian 10 March 2014.

64 McLuskie, K., 2013, pp. 195-206: Wenban-Smith, F., 2010, pp. 65-84.

65 Mary Stopes-Roe to Stephanie Green, November 14, 2012.

66 With thanks to Michele Nayman.

67 Pollock, D. (2014) Guardian May 21 at: http://www.theguardian.com/education/2014/may/20/harry-stopes-roe [accessed May $252014]$

68 Green, Public Lives, 2013.

69 National Archives, UK, 'Preserving Digital Collections' at: http://www.nationalarchives.gov.uk/archives-sector/digitalcollections.htm [accessed June 14 2014].

70 Smith, A. (2003) 'New-Model Scholarship: Destined for the Dustbin of History’, Perspectives on History, American Historical Association at: www.historians.org/publications-and-directories/perspectives-on-history/october-2003/new-modelscholarship-destined-for-the-dustbin-of-history/ [accessed 15/8/2014].

71 Brown, Clements, Grundy, Orlando Project at: http://orlando.cambridge.org/

72 Lesk, Michael (2014) 'Foreword' in Corrado, Edward M. and Heather Lea Moulaison (Eds) Digital Preservation for

Libraries, Archives and Museums (Lanham, M.D. and Plymouth, UK: Rowman and Littlefield), p. xv-xviii. 
73 Most recently Marie Stopes' name has been employed by the reproductive and sexual health enterprise Marie Stopes International, in reference to her early work in the field of preventative birth control: http://www.mariestopes.org.uk/ [accessed 25 August, 2014].

74 Hale, B., 'Royal Mail Honours Family Planning Pioneer', Daily Mail at http://www.dailymail.co.uk/news/article-1054749 [accessed 5 September 2012]. Warner, G., 'Marie Stopes is Forgiven Racism and Eugenics because she was Anti-Life', Telegraph at http://blogs.telegraph.co.uk/news/geraldwarner/5051109 [accessed 6 September 2012].

75 Fisher, K. (1999) 'Didn't stop to think, I just didn't want another one': the culture of abortion in interwar South Wales', Sexuality in Europe: Themes in Sexuality (Manchester: Manchester University Press), pp.213-233, p. 224.

76 Cohen, Deborah (1993) 'Private Lives in Public Spaces: Marie Stopes, the Mothers' Clinics and the Practice of Contraception', History Workshop Journal 35.1: pp. 95-116, p. 111.

77 Soldati, E. (2011) 'Sexuality and the Sphere's of Ignorance', Electronic Journal of Human Sexuality 14 at: www.ejhs.org/volume14ssssr1.htm/ [accessed 10 July 2014]. 